\title{
Organizational and Individual Promotion Strategies. The Use of Social Media among the Journalists of the Romanian Public Television
}

\author{
Senior Lecturer Rodica Melinda ŞUŢU, PhD \\ Faculty of Journalism and Communication, University of Bucharest \\ E-mail: rodicasutu@yahoo.co.uk
}

\begin{abstract}
This paper uses the Romanian Public Television as a case study to show that the strategies of promoting specific programs, media campaigns or celebrities through the new communication tools enabled by the digitalization, such as social media, significantly differ inside the company, either by department or by individual journalists. Depending on the manner they understand and accept the advantages of social media, different departments or individual journalists use the appropriate promotion strategies for their programs and media products. The author chose to employ qualitative methods, such as content analysis and semistructured interviews with journalists from different departments of the Romanian Public Television, in order to illustrate the differences as well as the mutual elements in the organizational culture of the media company. The fragmented organizational culture is the theoretical framework that supports this analysis, as it illustrates the difference of values and attitudes towards social media and the new promotion technologies.
\end{abstract}

Keywords: social media, new technologies, organizational culture, public television, promotion strategies.

\section{Introduction}

Media organizations all around the world have been gradually transformed by the evolution of technology. The interlocking of computers, information technol- 
ogy, telecommunication networks and the media content generated by newspapers, radio and television transformed the single media, traditional organizations into convergent media or multimedia organizations. Media professionals are required to extend their skills beyond their traditional comfort levels, facing changes in their professional routines and organizational cultures (Quinn \& Filak, 2005; Boczkowski, 2004; Rabasca, 2001).

The process of digitalization and the growing popularity of social media forced media companies to change their production, editorial and promotion strategies at different levels and paces, depending on their organizational culture. The author selected the Romanian Public Television as a case study because it is interesting to see how a traditional media organization, with a complicated human resources and production system faces the challenges of adopting the new technologies. The case study chosen by the author of this article illustrates how the use of social media as a promotion strategy tool differ significantly, both by department and individual journalists. For instance, while the News Department has live interviews on its social media page, in convergence with the personal Facebook pages of the journalists, as a promotion strategy for the upcoming newscasts on television, other departments or journalists only update their social media pages once a week or even two weeks. According to their level of acceptance of the necessity of social media, and their ability to understand and use the new technologies, various departments, reporters, producers and presenters employ the most appropriate strategies in order to promote their media products. The author of this article uses qualitative methods, such as content analysis and semi-structured interviews with journalists from different departments of the Romanian Public Television, because qualitative inquiry is more suitable to highlight the significant differences in the organizational culture of a media company. The theoretical framework of this research, fragmented organizational culture, successfully supports this analysis, as it illustrates the difference of values and attitudes towards social media and the new promotion technologies.

This original research, carried out for the first time in a Romanian media company, has the potential to provide important insight for media practitioners confronted with the challenges of adjusting to the transformations in their organization and trying to perform on a changing media market. They are usually involved in the development of their business or media products through the new technologies, either as free lancers or employees of a small or large media company. This article also provides valuable data for the scientists interested in investigating the effects of the new technologies and promotion strategies through social media on the culture of the media organizations, either in Romania or elsewhere. 


\section{Theoretical framework}

Romanian media is currently going through the process of adopting and implementing media convergence at organizational, technological and economic level. Convergence is a revolutionary form of journalism which is evolving in many parts of the world; therefore it may vary from country to country, from culture to culture both within countries and media companies. Media convergence is influenced by the power of digital technology, and the legal and economic factors in various countries and media trusts. The success of convergence depends on having journalists able to think multiple media and comfortable with working across several media platforms (Haile, 2003). Media convergence and the implementation of the new technologies forced the organization and its departments into adopting new digital production systems and devices and adapting to a new, dynamic workflow. As a direct consequence, the employees of public and private television stations are required to extend their skills beyond their experience in traditional media. Journalists are currently challenged to produce multiple products for multiple platforms, in order to reach a mass audience with interactive content, often on a 24/7 timescale (Quinn \& Filak, 2005). Pressured by the audience, competition and economic strings, media organizations and individual journalists face the task to tell stories using the most appropriate medium. The public gets more and more involved in the stories as digital communication provides multiple tools to select the level of interactivity while self-directing the content delivery. The new technologies allow audiences to interact with or even generate mass media content; consumers can now control when, where and how they access and relate to information of all kinds (Sutu, 2011).

\section{Digital media and organizational culture}

Radio and public television services in Europe are striving to produce highquality content, available across varied devices and platforms, and catered to reach different audiences. Journalists and managers of public service organizations are aware that innovative transformations are required in order to deliver public service news more effectively online. However, different media organizations have different strategies, both in terms of how news production is organized, and of how innovation processes are managed and supported. Some public service media organizations have teams dedicated specifically to developing new approaches and ideas for digital news. Particular attention is given to the effective use of social media, as more news use is driven by referrals and social media networks such as Facebook (Sehl et al., 2016). Some organizations, such as the Romanian Public Television, have a less formalized structure where innovation is based on individual staff members within the newsroom developing new ideas and building support for them. The author of this article selected the fragmented 
organizational culture theory to support this analysis, based on the case study of the Romanian Public Television, as it illustrates the difference of values and attitudes towards social media and the new promotion technologies. In this particular case, culture is regarded as an informally structured system, partially shared by the members of the organization, that can either adopt or reject different measures and strategies, according to their interests and acceptance level (Martin, 2002). Joanne Martin used a metaphor to express the essence of the fragmented organizational theory. So, if each member of an organization is attached a light bulb, when a problem becomes imminent, such as the implementation of a new organizational policy, or a significant change of policy inside the department, some lights will be on, showing who is actively involved (by approval or rejection), while others will be off, showing that the individuals are indifferent or not interested (2002).

\section{Qualitative methodology}

The author of this article uses qualitative methodology in order to scientifically investigate the promotion strategies departments and individual journalists of the Romanian Public Television apply on their programs and media products. The scientific inquiry is inductive, built as a result of semi-structured interviews and content analysis. The qualitative inquiry analyzes the subjective meanings and the social production of events and practices, by collecting non-standard data, and analyzing texts and images, rather than numbers and statistics. When studying latent practices and phenomena, the attempts of identification, measurement and adjustment to specific statistics, which quantitative traditional methodology does, might not bring positive results. As a matter of fact, social science scholars argued that the nature of the research subject points out the most appropriate methodology, and underlined the lack of productivity when it comes to debates on the best method.

The qualitative inquiry is considered a type of long time field observation, carried out in the proximity of the chosen phenomena, in order to investigate new perspectives and social context forms. Through extension, qualitative methodology fulfills the role of highlighting the essential differences and distinctive features of the phenomenon under study (Flick, 2009; Baran \& Davis, 2000). Qualitative research stands out for appropriateness of methods and theories, subjective perspectives of the participants, reflexivity of the researcher, variety of approaches and methods, the ability to understand the phenomena from the interior, construction of reality, usage of text and language as an empirical material, and flexibility of the research design (Jensen \& Jankowski, 2002; Flick, 2009; Babbie, 2013).

Qualitative methodology has been highly useful in mass communication research, either when investigating journalism education or practices and roles in newsrooms, selection and information gathering, production or delivery of the 
news. Furthermore, the work of qualitative social scientists helped in establishing various cultural environments appropriate for studying the new media practices which are developing in the context of the new technologies. As a matter of fact, the qualitative inquiry was the main method used in the last decade when examining the implications of adopting and implementing new technologies. When studying the adoption of new media production and promotion strategies in a single ownership company with various media platforms, or the merger of different ownership companies, or through comparing multimedia newsrooms using new technologies in different countries, the researchers used one or mixed qualitative methods: case studies, observation, content analysis, semi-structured or focus group interviews (Dupagne \& Garrison, 2006; Aviles et al., 2008; Singer 2004; Marjoribanks, 2003; Kung-Shankleman, 2003).

\section{Research design}

The main investigative tool used in this article is the qualitative interview, extensively employed in mass communication research, especially in the study of media organizations and their specific institutional procedures. The semi-structured interview is considered by social scientists" one of the most powerful methods in qualitative research because it allows investigators to step into the mind of another person, to see and experience the world as they do themselves" (McCracken, 1988:9).When researching mass communication topics, the qualitative interview is a valuable methodological tool, which generates the necessary data for building research questions (Spradley, 1979; Briggs, 1986). The utilization of qualitative interview is regarded as a useful method to provide essential research data; scientists argue that the in-depth interview is an active process of construction of reality, through circumstances that generate meanings that the interviewer might not be aware or willing to acknowledge (Gobrium \& Holstein, 2002).

The use of qualitative interview in researching the promotion strategies trough social media has the role to facilitate the understanding of the implications and meaning of the new media technologies for the work of journalists or newsrooms activities, to highlight the changes in the organizational culture and the professional identity of the journalists, to understand the challenges it brings to the values, roles and routines of media professionals. There is no definite rule on the ideal number of interviewees, but McCraken and Wengraf recommend eight respondents in order to obtain relevant findings from semi-structured interviews (McCracken, 1988; Wengraf, 2001). The author of this study selected ten respondents- reporters, editors, presenters, camerapersons and producers that have the ability to illustrate a wide range of indicators of the transformations urged by the use of social media on the organizational culture. The interviewees were affected by different aspects of media convergence, such as adopting new work practices 
in the newsroom, delivering the message through multiple channels and using social media as a communication tool with the target audience.

Qualitative content analysis of the Facebook pages of various programs, from news to day time entertainment, as well as the individual social media pages of different journalists was carried out for 12 months, October 2015 to October 2016. The research questions are most appropriate in new areas of scientific investigation when little is known about the relationships among variables and in which there is not enough literature that is applicable (Shoemaker et al., 2004). In this particular case, there is a legitimate need for inductive research as the area of the new technologies and promotion strategies through social media in Romania is still a virgin territory for researchers. The research questions used in this qualitative investigation are:

RQ1: How does the Romanian Public Television use social media as a promotion strategy at the organizational level?

RQ2: How do the individual departments of the Romanian Public Television use social media to promote their media products and programs?

RQ3: What are the strategies individually employed by the journalists of the Romanian Television in order to promote their activities through social media?

\section{Results and discussion}

Depending on the manner they understand and accept the advantages of social media, different departments or individual journalists use the appropriate promotion strategies for their programs and media products. While the news department has live interviews on its social media page, in convergence with the personal Facebook pages of the presenters, as a promotion for the upcoming newscasts on television, other departments or journalists only update their social media pages once a week or even two weeks.

News editor M. Popa, producer R. Tiniche and anchor A. Barbulescu share on their Facebook pages the live interviews they did on the official Facebook page of the News Department of the Romanian Public Television, Stirile TVR. Relevant examples are the Facebook live interviews to promote the night news program "Ora de Stiri/ News Hour", such as the interviews with a tourist agent about the popular destinations for the summer holidays, or the interview with the manager of the Romanian Village Museum. On the other hand, the daily noon debate and analysis program "Actual pe 2" only updates its Facebook page once a week, and the presenter does not even have a personal one. One of the producers, R. Brumariu, says that more interaction with the viewers through the new technologies is needed as the content is interesting, but the manner of presentation is not appealing enough to the young audience. Brumariu criticizes the management for 
unwillingness to provide feedback to the comments and complains the viewers make on the Facebook page of the program.

Some journalists use Facebook as a promotional tool for their hobbies, mirror of personal life, platform to interact with fans, or humanitarian and voluntary work with different NGOs. News anchor M. Radulescu uses Facebook to promote his work as a volunteer for the Casa Sperantei hospice and posted photos from the marathon he ran to raise money for the this organization. M. Radu, former news anchor and current host of various entertainment programs is very active on his Facebook page and personal website, where he promoted the launch of his first cook book "Povesti cu gust/ Tasty stories", with hourly posts, photos and videos.

The preference of the audience to consume news and entertainment, as well as to interact with the presenters and the producers through the new technologies is reflected by the situation described by the news reporter A. Petrisor, who expressed his surprise to discover that the stories he broadcasts are more popular on Facebook than on television. He gave the example of an investigative newspackage he did for the Romanian Public Television, which disclosed that a famous story by the British journalists from Sky News about Romanians selling guns to terrorists was actually fabricated. The paradox was the story A. Petrisor posted on his Facebook page, with video attached, had twice as many users as the number of the viewers on television, where the original investigative report was broadcast. This example stands for many other situations that illustrate the increasing popularity of social media as a source of news stories among the audience of the Romanian Public Television.

At the organizational level, the Facebook pages of the channels TVR1, TVR2, TVR3, TVR International promote the major campaigns of the organization such as TVR 60, reflecting the history of the Romanian Television, through interviews and features with the current and former outstanding employees. In that respect, all the journalists interviewed and the social media monitored for the content analysis of this article included on their Facebook pages references to different aspects of the campaign, either produced by their department or by other departments of the Romanian Public Television. For instance, anchor M. Constantin, reporter C. Csiki and cameramen S. Eseanu shared, on their Facebook page, the social media page of the News Department, Stirile TVR, where the story "Henri Coanda-Istoria in stiri/ Henri Coanda-History in the news" was posted. There are also instances when TVR as an organization planned extensive campaigns to raise awareness about the role and the mission of the public service television, such as "Dorobanti 191. Ne priveste TVR/ TVR concerns us". While the feature reports and interviews were produced mostly by the News Department, the official Facebook pages of the channels TVR1, TVR2, TVR3 and TVR International, Stirile TVR Facebook page, as well as the personal pages of the producers and reporters shared differ- 
ent topics of the campaign. A similar situation occurred with "Ambasador fara granite/ Ambassador without borders" a series of interviews and feature stories with outstanding Romanian artists, doctors, politicians, professors, writers and priests that live abroad. The campaign was produced by TVR International, was broadcast in the newscasts of TVR1 and TVR2 and promoted intensively on the Facebook pages of all TVR channels. The reporters involved in the production of "Ambasador fara granite/ Ambassador without borders" also promoted the topics they covered on their personal Facebook pages.

On the other hand, when the campaigns "Ei nu au nicio vina/ They are not to blame", about the stories of the refugees camped at the border of Serbia and Croatia, and "Povesti din Kandahar/ Stories from Kandahar", covered by reporter A. Petrisor, were aired on TVR1, the organization only promoted them on television, while the News Department also shared the stories on their Facebook page Stirile TVR. The same strategy applied to the campaign "Pacient de Romania/ Patient in Romania", a series of interviews and investigative reports about the problems of the national health system, covered by reporters D. Brancus, A. Archip and L. Fronoiu. The reporters themselves posted updates and attached videos and links to Stirile TVR and the Facebook page of the News Department, Stirile TVR.

\section{Conclusion}

TVR as a media organization illustrates the theory of fragmented organizational culture: an informally structured system, partially shared by the members of the organization, as they interact with their audience through social media, and experiment different events and contextual aspects (Martin, 2002). The culture manifested inside the Romanian Public Television is neither coherent nor uniform when it comes to the values and beliefs of its members. However, the members of the organization are united by sharing the same problems, live similar experiences and share a mutual interest in the major objectives of the organization.

The results show that individual journalists and television channels use both organizational and individual strategies. The use of social media among TVR departments and programs differ significantly in frequency and strategy; only for major campaigns such as TVR60, co-production of various departments such as "Ambasador fara granite/ Ambassador without borders" or the launch of new programs and introduction of new anchors and presenters there is a social media strategy at the organizational level. Individual journalists usually prefer to post information and video about their own work or independent activities on social media. Journalists promote specific programs, by posting or sharing the information about various products and campaigns of the organization when they are actively involved or it fits their professional and personal values and interests. 
The combination of two qualitative methodological tools, content analysis and semi-structured interviews, provided in depth analysis of the different aspects of the process adopting the new technologies and implementing social media promotion strategies at the Romanian Public Television. The findings of the content analysis are confronted with the information gathered with the semi-structured interviews. The validity of the data provided by some of the respondents is further verified through the questions the researcher asked other interviewees; it also plays an important part in highlighting the potential discrepancies and show latent problems that are difficult to identify at the beginning of the research process. However, further research is necessary to investigate the changes in the Romanian media organizations, at a wider range, through quantitative methodology. This particular research has the potential to provide a valuable starting point for the scientists interested in investigating the effects of new technologies on media organizations, either in Romania or elsewhere. The results of this scientific investigation are also helpful for the media managers interested in adopting new technologies and applying innovative promotion strategies in their organizations.

\section{References}

1. Avilés, J.A., Meier, K. , Kaltenbrunner, A., Carvajal, M. \& Kraus, D. (2009). Newsroom integration in Austria, Spain and Germany. Journalism Practice, 3(3), 285-303.

2. Babbie, E.R. (2013). The Practice of Social Research (14 ${ }^{\text {th }}$ edtn) Belmont, CA: Wadsworth.

3. Baran, S.J., \& Davis, D.K. (2000). Mass Communication Theory. Foundations, Ferment and Future ( $2^{\text {nd }}$ edtn) Belmont, CA: Wadsworth.

4. Boczkowski, P.J. (2004). The mutual shaping of technology and society in videotext newspapers: Beyond the diffusion and social shaping perspectives. The Information Society, 20(4), 255-267.

5. Briggs, C. (1986). Learning how to ask: A sociolinguistic appraisal of the role of the interview in social science research. Cambridge, UK: Cambridge University Press

6. Dupagne, M., \& Garrison, B. (2006). The meaning and influence of convergence. A qualitative case study of newsroom work at the Tampa News Center. Journalism Studies, (7)2, 237-255.

7. Feldman, M.S. (1991). The meanings of ambiguity: Learning from stories and metaphors. In P. Frost, L. Moore, M. Louis, C. Lundberg \& J. Martin (eds), Reframing organizational culture (pp.145-56). Newbury Park, CA: Sage.

8. Flick, U. (2009). An introduction to Qualitative research ( $4^{\text {th }}$ edtn). London: Sage.

9. Gobrium, J., \& Holstein, J. (2002). Handbook of interviewing: Context and method. Thousand Oaks, CA: Sage.

10. Haile, J. (2003), Creating a change culture: A case study of the Orlando Sentinel's transition to a multimedia company, Inside Out Media. 
11. Jensen, B.K. \& Jankowski, N.W. (2002). A handbook of Qualitative Methodologies for Mass Communication Research.( $2^{\text {nd }}$ edtn). London: Routledge.

12. Kung-Shankleman, L. (2003). Organizational Culture inside the BBC and CNN. In S. Cottle (Ed), Media Organizations and Production (pp. 77-96). London: Sage.

13. Marjoribanks, T. (2003). Strategizing Technological Innovation: The Case of News Corporation. In S. Cottle (Ed), Media Organizations and Production (59-75). London: Sage.

14. Martin, J. (2002). Cultures in organizations: Three perspectives. Oxford University Press

15. McCracken, G. (1988). The Long Interview. Newbury Park, CA: Sage.

16. Meyerson, D.E. (1991). Normal ambiguity? A glimpse of an occupational culture. In P. Frost, L. Moore, M. Louis, C. Lundberg \& J. Martin (eds), Reframing organizational culture (pp.131-144). Newbury Park, CA: Sage.

17. Quinn, S. \& Filak, V. (2005), Convergent Journalism, Burlington: Elesevier.

18. Rabasca, L. (2001). The next newsrooms. Presstime, 7, 44-50.

19. Schneider, B., Ehrhart, M.G., \& Macey, W.H. (2013). Organizational climate and culture. Annual review of psychology, 64, 361-388.

20. Sehl, A., Cornia, A., \& Nielsen, R.K. (2016). Public Service News and Digital Media. Reuters Institute Reports.

21. Shoemaker, P., Tankard, J.W., \& Jr, Lasorsa, D.L. (2004). How to build social science theories. Thousand Oaks, CA: Sage.

22. Singer, J.B. (2004). Strange bedfellows? The diffusion of convergence in four news organizations. Journalism studies, 5(1), 3-18.

23. Spradley, J.P. (1979). The Ethnographic Interview. New York: Holt, Rinehart and Winston.

24. Șuțu, M.R. (2011).Convergence, the new way of doing journalism. Romanian Journal of Journalism and Communication,1(6),48-53.

25. Wengraf, T. (2001). Qualitative Research Interviewing. Thousand Oaks, CA: Sage. 